Original article

\title{
Estimation of prevalence and screening of communication disorders in North and Middle Andaman and Nicobar Islands
}

\author{
Prashanth Prabhu*, Sreeraj Konadath, Vimala Jayakrishna Kasturi, Vivek Arumugam, \\ Malavi Srikar, Ashique Rahman, Ashiq Abdul Rahman, Aswathy Pulimootil Biji \\ All India Institute of Speech and Hearing, Manasagangothri, Mysuru, India
}

\section{A R T I C L E I N F O}

\section{Keywords:}

Prevalence

Communication disorders

North and Middle Andaman

\begin{abstract}
A B S T R A C T
Objective: Andaman and Nicobar Islands is a union territory in the Indian sub-continent. Though housing a highly diverse and large population, there is very limited data regarding the prevalence of communication disorder in this region. This information would play a crucial role in creating awareness amongst the people of the islands regarding communication impairments, providing rehabilitation services, and improving policies and facilities for the affected individuals.

Method: The study was conducted in two phases. The first phase involved a door to door survey. The survey was carried out across towns in North and Middle Andaman by NSS student volunteers and staffs of All India Institute of Speech and Hearing, Mysuru. During this phase, individuals with communication disorders were identified and referred for a two-day camp. The second phase involved diagnosis and rehabilitation of these referred individuals in a campsite set in a well accessible point in the city of Mayabunder.

Results: $3.38 \%$ of the surveyed population was referred for the camp. Hearing impairment was found to be more prevalent than language and speech disorders. It was also found that delayed birth cry, low-birth weight and premature delivery were the major risk factors of communication disorders in the region. Amongst the referred individuals who attended the camp, $46.8 \%$ of ear-related issues and $53.2 \%$ of speech and language disorders was estimated. It was also observed that males were more affected by communication disorder than females. Conclusion: The high prevalence values indicate the need for immediate action in terms of facilities and infrastructure in these regions for enabling a better quality of life of individuals with communication disorders.
\end{abstract}

\section{Introduction}

Communication is the act of sending and receiving information between two or more individuals. This information exchange can occur broadly in two modes: verbal (Speech, writing) and non-verbal (gestures, body language). Successful communication is important for an individual's positive integration into society and overall emotional wellbeing. Any disruption in an individual's ability to detect, comprehend, or apply language and speech to effectively engage in discourse can be termed as a communication disorder. ASHA stated that communication disorder is "an impairment in the ability to receive, send, process and comprehend concepts or verbal, non-verbal and graphic symbol system".

It is important to obtain epidemiological data related to speech, language, and hearing issues to understand the holistic status of communication disorders. Epidemiology provides information regarding the incidence, prevalence, and distribution of diseases and other factors relating to health. Prevalence is a measurement of all the individuals of a given population with specific characteristics at a particular point of time. Availability of such data can aid health care professionals in planning service delivery, checking the efficacy of existing rehabilitation programs, and making comparisons between typical and atypical development. It can also influence the policy makers into framing policies that help integrate persons with communication disorders into society, promote their independence, and enable them to live a full and dignified life.

The prevalence of disability percentages across populations in selected countries around the world has been published in the World Report on Disability - 2011. Literature has revealed that hearing impairment is the most common cause of communication disability around the world. India is the second most populous and geographically, the seventh largest country in the world. Hence, obtaining epidemiological information is of high importance. It is a developing country, has shown to have a higher prevalence than other developed

\footnotetext{
* Corresponding author. All India Institute of Speech and Hearing, Manasagangothri, Mysore, 570 006, India.

E-mail address: prashanth.audio@gmail.com (P. Prabhu).
} 
countries. ${ }^{2}$ The World Health Organization 2009, reported that around 63 million people suffer from hearing impairment in India. ${ }^{3}$ According to the National Sample Survey Organization 2011, the population of disabled persons with hearing impairment was reported to be $19 \%, 7 \%$ with speech handicap and $6 \%$ with intellectual disability. ${ }^{4}$

India is also a country with a highly diverse population. Socioeconomic, cultural, and geographical factors influence the prevalence of communication disorders across various parts of the country. A small number of area-specific prevalence studies are previously conducted within India. $^{5-11}$ These indicate a difference in the proportion of the population affected per area. A survey conducted by Sinha et al..$^{5}$ in the rural population of Gujarat reported an overall $4.09 \%$ prevalence of communication disorders. A higher prevalence of ear-related than speech and language related communication disorders was found. Mishra et al. ${ }^{6}$ on the other hand, reported a much higher prevalence (15.14\%) of communication disorders in the rural areas of Lucknow district. A study conducted by Das et al. ${ }^{7}$ in the rural areas of Kolkata district, reported a high prevalence of stroke leading to communication impairments.

Ganesh et al. ${ }^{8}$ and Bhagya et al. ${ }^{9}$ carried out survey studies that indicated a high prevalence of mental disability in different communities of Karnataka. Konadath et al. ${ }^{10}$ reported that among the 15,441 individuals surveyed in a rural district of Karnataka, the prevalence of communication disorders was found to be around $6.07 \%$. On the other hand, Konadath et al. ${ }^{11}$ reported a prevalence of communication disorders to be $3.63 \%$ in the Lakshadweep group of islands.

The difference across regions could be due to a variety of reasons like cultural differences, ${ }^{12}$ lifestyle, ${ }^{13}$ habits, literacy rates, ${ }^{14}$ economic status, living conditions (urban vs rural), and geographical location, including availability and access to health care. Understanding these factors and their influence on communication disorders is important to help contribute to the overall development of the country and improve the quality of life of persons with communication disorders. Hence, the data from the previous studies indicate an urgent need to carry out more such studies on a larger scale to predict the spread of communication disorders across the country.

Andaman and Nicobar Islands, a union territory in India is one such area with limited access to services and facilities related to communication disorders, when compared to the mainland. The Census on India-2011 reported that the Andaman and Nicobar group of islands are inhabited by a population of 379944 people. ${ }^{4}$ Though smaller by area, these islands have a highly diverse population with more than six languages being spoken, five religions being practiced, and multiple cultures, including those from the mainland and some native tribal populations. The North and Middle Andaman has shown to have a population of 105597, of which 54861 were males, and 50736 were females. $^{4}$

Although a few studies have reported a higher prevalence of communication disorders across different regions of India, there are limited studies which have indicated the status of communication disorders in these remote islands away from the mainland. Konadath et al. ${ }^{15}$ attempted to study the prevalence of communication disorders in Port Blair, Andaman and Nicobar Islands. They reported that $4.12 \%$ of the population that was surveyed got referred for the camp. Amongst the referred individuals who participated in the camp, the prevalence of ear-related problems was estimated to be $47.76 \%$, and that of speech and language disorders came up to $52.24 \%$. However, the data of Port Blair is from an urban population who are esposed to multiple-languages and have better facilities. The north and middle Andaman region is mostly rural and further separated from the mainland. The main occupation is agriculture and are from a low socio-economic status. Most of the people from north an middle Andaman speak only one language (mother tongue). Considering all the above mentioned differences, it is essential that estimation of prevalence and screening for communication disorders has to be carried out in North and Middle Andaman regions. Hence, the current study aimed to document the prevalence of communication disorder in the Middle and North regions of the Andaman and Nicobar Islands. In addition, it is also attempted to screen individuals for communication disorder in the Middle and North regions of the Andaman and Nicobar Islands.

\section{Methods}

The present study was carried out in two phases. Phase one included a door to door survey. The survey was carried out using a High-risk Register (HRR) ${ }^{16}$ to identify individuals with communication disorders. The survey was conducted in the towns of Diglipur, Mayabunder, and Rangat.

Phase two included a two-day camp held at Mayabunder, a place at the center of middle and North Andaman. This was held for two consecutive days and remained open for $8 \mathrm{~h}$ per day. Here, the identified individuals were evaluated and advised regarding the next best course of action. All India Institute of Speech and Hearing, Samagra Shiksha Abhiyan (SMSA), Union Territory of Andaman and Nicobar Islands, National Service Scheme (NSS), University of Mysuru and Ali Yavar Jung National Institute of Speech and Hearing Disabilities (Divyangjan), Secunderabad, provided the resources for the door-todoor survey, evaluation and intervention services delivered.

\section{Participants}

A total population of 30307 from Middle and North Andaman was surveyed for communication disorders, making up the participants of the study. These were native residents of the Andaman Islands. The required information was collected from adults in the household. Using the HRR, ${ }^{15}$ those individuals identified as 'at risk' for communication disorders were considered as the participants for the second phase of the study.

\section{Procedure}

In Phase 1, the door-to-door survey was conducted by 96 NSS volunteers and four staffs from AIISH. The volunteers belonged to two units and were further divided into smaller groups for more efficient coverage of the population. The survey was carried out for five consecutive days across the towns of Diglipur, Mayabunder, and Rangat. The volunteers comprised of undergraduate students of Speech and Hearing and postgraduate students of Speech-Language Pathology or Audiology. The staff comprised of qualified audiologists or speechlanguage pathologists, with at least a master's degree. Before commencing the survey, an orientation was given to the volunteers by the staffs accompanying the volunteers. This included instructions regarding the what and how of the information to be collected during the survey.

A question and answer-based interview using a general questionnaire (Appendix I) were carried out at each household to identify individuals with communication disorders. This questionnaire provided information such as demographics, the total number of persons in each household, presence of any communication disorders in these persons and further information regarding the person with the disorder (age of onset, progression, etc.). The individuals identified as having communication disorders were referred to the camp for further evaluation and guidelines for the management of the same. A total population of 30307 was surveyed across five days, and 1026 individuals were referred to attend the camp.

In phase two of the study, a two-day screening camp was carried out in Mayabunder. Here, evaluation and habitation or rehabilitation were carried out for the two hundred and twenty individuals who reported to the campsite. Each of them was first registered and then referred to the different sectors of services in and around the campsite as per their need. The volunteers provided directions to the individuals at each step or upon completion at each sector for the smooth functioning of the 
camp.

First, the HRR developed at the All India Institute of Speech and Hearing ${ }^{15}$ was administered on each reporting to the campsite. The gathered information included age, gender, region, educational history, and socio-economic status of the individual. The presence of any causative or risk factor such as any medical and familial history was noted. The medical history and possible causative factors were divided into three segments: Prenatal, Natal, and Post-natal history. It was administered particularly in the case of children.

The prenatal history checked for excessive vomiting (after the first trimester), elderly pregnancy ( $>35$ years of age), the occurrence of viral/bacterial infections, hyper/hypotension or high/low blood sugar level during the gestational period. It also looked for a history of abortions, Rh incompatibility, the habit of alcohol consumption or smoking, and intake of ototoxic medication. The natal history posed queries regarding the low birth weight of the infant $(<1.5 \mathrm{Kg})$, premature delivery, birth asphyxia, delayed birth cry ( $>20 \mathrm{~s}$ ), infantile jaundice, NICU admission, APGAR scores, abnormal delivery or any other associated complications. The post-natal history checked for the presence of any craniofacial anomalies, syndromes, bacterial/viral infections, convulsions, history of acute/chronic suppurative otitis media (ASOM/CSOM), decreased vegetative skills, trauma to head/neck, cancer/tumours, cerebrovascular accidents, presence of any degenerative diseases or functional/psychological disorders, voice abuse/ misuse and history of noise exposure. Depending on their complaint and history the individuals were directed to the different services set up at the campsite such as speech and language evaluation, psychological evaluation, ENT consultation, audiological evaluation, hearing aid trial and ear mold fitting.

The individuals reporting ear-related problems were directed to an ENT evaluation. The ENT specialist took down a detailed case history, carried out an otoscopic evaluation and hence prescribed any medications necessary. Wax clearance was also done if it was required. The individuals were then directed for audiological evaluation, if necessary. Pure tone audiometry was carried out by volunteers in a closed room away from major noise sources. The thresholds for air conduction were obtained for $0.5 \mathrm{kHz}, 1 \mathrm{kHz}, 2 \mathrm{kHz}$, and $4 \mathrm{kHz}$ and bone conduction were measured across $1 \mathrm{kHz}, 2 \mathrm{kHz}$ and $4 \mathrm{kHz}$ pure tones. Testing was carried out using a portable type II audiometer. The type II audiometer has the facility of carrying out $\mathrm{AC}$ and $\mathrm{BC}$ at the frequencies of for $0.5 \mathrm{kHz}, 1 \mathrm{kHz}, 2 \mathrm{kHz}$, and $4 \mathrm{kHz}$. The Modified Classification System ${ }^{16}$ was employed to arrive at a diagnosis for the degree of hearing loss. Immittance audiometry (tympanometry and reflexometry) was employed to examine the middle ear status of the patient using a Type III Immittance Meter. Type III immittance meter had the facility of recording tympanometry and automatically record acoustic reflexes at $0.5 \mathrm{kHz}$. Pure tone audiometer and immittance were calibrated according to the International standards specified by the manufacturer.

Upon completion of the audiological evaluation, appropriate referrals were made for the individuals. This included hearing aid trial and speech-language evaluation. The individuals received a trial with digitally programmable hearing aids. This was carried out by programming the aid in accordance with the NAL-NL1 prescriptive formula. Performance with the hearing aid, subjective preference, and opinions regarding audibility and comfort were considered for recommending the use of the hearing aid. The aid was prescribed to all individuals fitting into the criteria of hearing disability as per the RPWD Act. ${ }^{17}$ Finally, counseling regarding the usage, maintenance, and realistic expectations from the aid was provided.

Individuals with speech and language complaints were referred for a speech and language evaluation. This was carried out by volunteers under the supervision of a qualified speech-language pathologist. For persons with complaints related to speech, an oro-motor examination was carried out. Standardized tools were administered to check for any articulation (Hindi articulation test), fluency (Stuttering severity index), dysarthria (Frenchay dysarthria Assessment) or voice
(Consensus of auditory-perceptual evaluation of voice) related problems. They were also assessed for any swallowing issues. Individuals presenting with language related complaints were screened using tools such as the Receptive-Expressive Emergent Language Scale or 3Dimensional Language Acquisition Test. Those individuals who reported complaints relating to mental abilities were further recommended a psychological evaluation. Qualified clinical psychologists carried out the evaluation using Vineland Social Maturity Scale-Indian adaptation and Developmental Screening Test. Those individuals with maxillo/craniofacial anomalies or voice complaints were referred to the ENT specialist for a consultation.

The individuals were provided a detailed counseling here any queries they had were answered. They were informed regarding the nature of the disorder, the appropriate intervention strategies to be used at home, and about different methods of generalization for achieved goals or responses. During the counseling, relevant home training materials for hearing, language, fluency, voice, and articulation disorders were distributed and explained. All the individuals requiring a detailed evaluation were referred to the mother institute: All India Institute of Speech and Hearing, Mysuru for further investigations and management.

\section{Results}

A total population of 30307 was surveyed across the three towns of Diglipur, Mayabunder, and Rangat. Among the population surveyed, $1026(3.38 \%)$ were identified to be at risk for communication disorders using the High-Risk Register. Among the 1026 individuals, 533 (52\%) were males, and 493 (48\%) were females. The gender wise distribution of hearing impairment, language disorder and speech disorder from the survey data is provided in Table 1 . The results show that hearing impairment was found more followed by speech disorder and language disorder in both males and females.

The age wise distribution of communication disorders are provided in Table 2. The results show that hearing impairment was reported to be more in the age group of 16-60 years. Langauge disorders were found to be more in the age group of $<15$ years. However, speech disorder was more in the age group of 16-60 years.

An item analysis of risk factors was carried out based on the survey data. The results showed that the item-total correlation was found to be more for the risk factors namely pre-mature delivery, low-birth weight and delayed birth cry. However, the risk factors such as history of abortions, consanguinity and neonatal jaundice contributed less for the communication disorders. The result of item analysis are provided in Table 3 which shows the item total correlations.

Following the survey, an assessment camp was held for two consecutive days. Among the 1026 individuals referred, 357 individuals reported to the campsite. 187 (52\%) of these 357 individuals were found to have ear-related issues like reduced hearing sensitivity, itching, ear pain, ear discharge, blocking sensation or fullness of the ear, and tinnitus. 139 (39\%) of the reported population indicated some speech and language related issues such as articulation, voice or fluency issues, maxillofacial anomalies, motor speech disorders, language delays, and/or academic difficulties. 31 (9\%) of the individuals attending the camp reported to have some ear related and speech and language problems. Further, 99 individuals belonged to the pediatric population

Table 1

Gender-wise distribution of communication disorders from the survey data.

\begin{tabular}{lllll}
\hline & $\begin{array}{l}\text { Hearing } \\
\text { Impairment }\end{array}$ & $\begin{array}{l}\text { Language } \\
\text { Disorders }\end{array}$ & $\begin{array}{l}\text { Speech } \\
\text { Disorders }\end{array}$ & Total \\
\hline Males & 243 & 132 & 158 & 533 \\
Females & 198 & 141 & 154 & 493 \\
\hline Total & 441 & 273 & 312 & 1026 \\
\hline
\end{tabular}


Table 2

Age-wise distribution of communication disorders.

\begin{tabular}{|c|c|c|c|c|c|}
\hline \multirow{3}{*}{$\begin{array}{l}\text { Hearing } \\
\text { Impairment }\end{array}$} & & $<15$ years & $16-60$ years & $>60$ years & Total \\
\hline & Males & 53 & 123 & 67 & 243 \\
\hline & Females & 37 & 101 & 60 & 198 \\
\hline \multirow[t]{3}{*}{ Language Disorder } & & $<15$ years & $16-60$ years & $>60$ years & Total \\
\hline & Males & 73 & 37 & 22 & 132 \\
\hline & Females & 67 & 55 & 19 & 141 \\
\hline \multirow{3}{*}{$\begin{array}{l}\text { Speech } \\
\text { Disorder }\end{array}$} & & $<15$ years & $16-60$ years & $>60$ years & Total \\
\hline & Males & 59 & 87 & 12 & 158 \\
\hline & Females & 72 & 61 & 21 & 154 \\
\hline
\end{tabular}

Table 3

Results of item analysis of risk factors for the survey data.

\begin{tabular}{ll}
\hline Risk Factor & Item total correlations \\
\hline Pre-matured delivery & 0.27 \\
Low birth weight & 0.26 \\
Dealyed Birth cry & 0.38 \\
History of abortions & 0.02 \\
Consanguinity & 0.02 \\
Neonatal jaundice & 0.05 \\
\hline
\end{tabular}

( $<15$ years of age), 175 were adults (between 15 and 60 years of age), and 83 belonged to the geriatric population ( $>60$ years of age). This classification was based on the $\mathrm{HRR}^{18}$ used during the survey.

\subsection{Ear-related problems}

Individuals with ear-related problems were first directed to an ENT investigation. A total of 187 individuals were evaluated by the ENT specialist. Among these individuals, 77 (41.8\%) were found to have otorrhea, and other ear infections, 7 (3.7\%) reported otalgia, 5 (2.7\%) were found to have eustachian tube dysfunction, $3(1.6 \%)$ complained of tinnitus and $15(8 \%)$ were found to have other issues such as imparted wax, and $80(42.8 \%)$ reported hearing loss not attributed to outer/middle ear issues. The occurrence of otalgia, otorrhea, and the ear infection was found to have a higher prevalence in the adult age group followed by the pediatric age group, with a lesser prevalence in the geriatric age group. The individuals identified with these ear related problems were provided with appropriate medical services such as clearance of wax or ear discharge and appropriate medication. The occurrence of sensorineural hearing loss was found to be highest in the geriatric age group followed by the pediatric group. Refer Fig. 1 for the age-wise distribution of the different ear-related issues among the reported individuals.

As a rehabilitative measure, 98 (53.26\%) individuals were given medications according to their need for treatment. These individuals were further recommended for an audiological examination. A total of 77 individuals were found to have hearing loss, of which eight belonged to the pediatric population ( $<15$ years of age), 36 were adults (between the ages of 15 and 60 ), and 33 belonged to the geriatric population ( $>60$ years of age).

\subsection{Speech and language disorder}

Speech and language evaluation was done for 170 out of the 357 individuals. It was found that 139 of them had problems only related to speech and language skills. Four of the reported individuals were found to have clinically normal speech and language skills. It was also found that 31 of these individuals reported both, ear related and speech-language problems. Of the 139 individuals with speech-language issues, 75
(53.95\%) of the evaluated individuals were identified as having language and $64(46.05 \%)$ as having speech-related disorders.

Among these 75 individuals, $66(88 \%)$ belonged to the pediatric population, and $9(12 \%)$ individuals were adults. It was found that among the 75 individuals with language disorders, 10 (13.3\%) were diagnosed with a pure spoken language disorder (SLD), 39 (52\%) with intellectual disability (ID), 3 (4\%) children were diagnosed to fall under Autism Spectrum Disorders (ASD), 1 child (1.3\%) was diagnosed with attention deficit hyperactive disorder (ADHD), and 13 (17.3\%) children were found to have academic difficulty, with the risk of learning disability (LD). It was found that among the 31 children reporting ear related and speech-language issues, 21 had spoken language disorder with hearing impairment (HI) and 10 had both hearing impairment and intellectual disability. The gender distribution of the language disorders identified is represented in Fig. 2.

Among the 64 individuals reporting speech related issues, 10 (15.62\%) were found to have voice disorders, 35 (54.68\%) having issues with fluency, 10 (15.62\%) with speech sound disorders (SSD), 2 (3.12\%) with motor speech disorders (MSD), 4 (6.25\%) having maxillofacial anomalies (MFA) and $3(4.68 \%)$ individuals were evaluated to have multiple speech and language disorders (multiple SLD). The gender distribution of speech disorders evaluated in North and Middle Andaman is represented in Fig. 3.

Among the 170 individuals reporting for a speech-language evaluation, $104(61.2 \%)$ were referred for a psychological evaluation. Adequate counseling and training strategies were provided to these individuals by a qualified psychologist. For those with speech and language issues, approximately 148 individuals attended speech therapy and counseling. Appropriate therapy techniques were demonstrated for adults and children in the presence of their caretakers. Home training programs were also handed out and explained.

\section{Discussion}

A total population of 30307 was surveyed by the NSS student volunteers during the door-to-door survey, among which 1026 (3.38\%) were identified to be 'at risk' for communication disorder and were referred to the camp. The delayed birth cry, low birth weight and prematured delivery were the major risk factors for communication disorders. The results are in consensus with previous studies which also report that these risk factors can lead to communication disorders. ${ }^{18,19}$ The lack of appropriate medical facilities and low socio economic status might have lead to these risk factos causing communication disorders. Consanguinity is not common in North and Middle Andaman and it was not a major risk factor.

A total of 357 individuals reported at the campsite to avail the various evaluation and rehabilitation services. 139 (38.9\%) were found to have speech and language related issues, 187 (52.3\%) reported with ear-related issues, and $31(8.6 \%)$ were found to have both speech language and ear related issues. The prevalence of communication disorders in North and Middle Andaman Islands (3.38\%) almost mirrored that found in the Lakshadweep Islands $(3.63 \%)$ by Konadath et al. ${ }^{11}$ and Port Blair, Andaman and Nicobar Islands $(4.12 \%)$ by Konadath et al. ${ }^{15}$ It also showed a similar prevalence rate to some parts of the Indian mainland, like some rural parts of Gujarat (4.09\%) and Karnataka $(6.07 \%)$ as reported by Sinha et al. ${ }^{5}$ and Konadath et al., ${ }^{10}$ respectively. These findings could be attributed to the similarities in living conditions, awareness or access to health care found in the island territories and various rural parts of the mainland.

\subsection{Ear-related problems}

An age-wise comparison of the ear-related problems concerning hearing abilities was found to be more in the geriatric population. ${ }^{18-20}$ This could be attributed to well-established age-related changes in the hearing mechanism. A gender wise comparison of ear-related issues 




Fig. 1. Age-wise distribution of ear-related disorders evaluated in North and Middle Andaman \& Nicobar Islands.

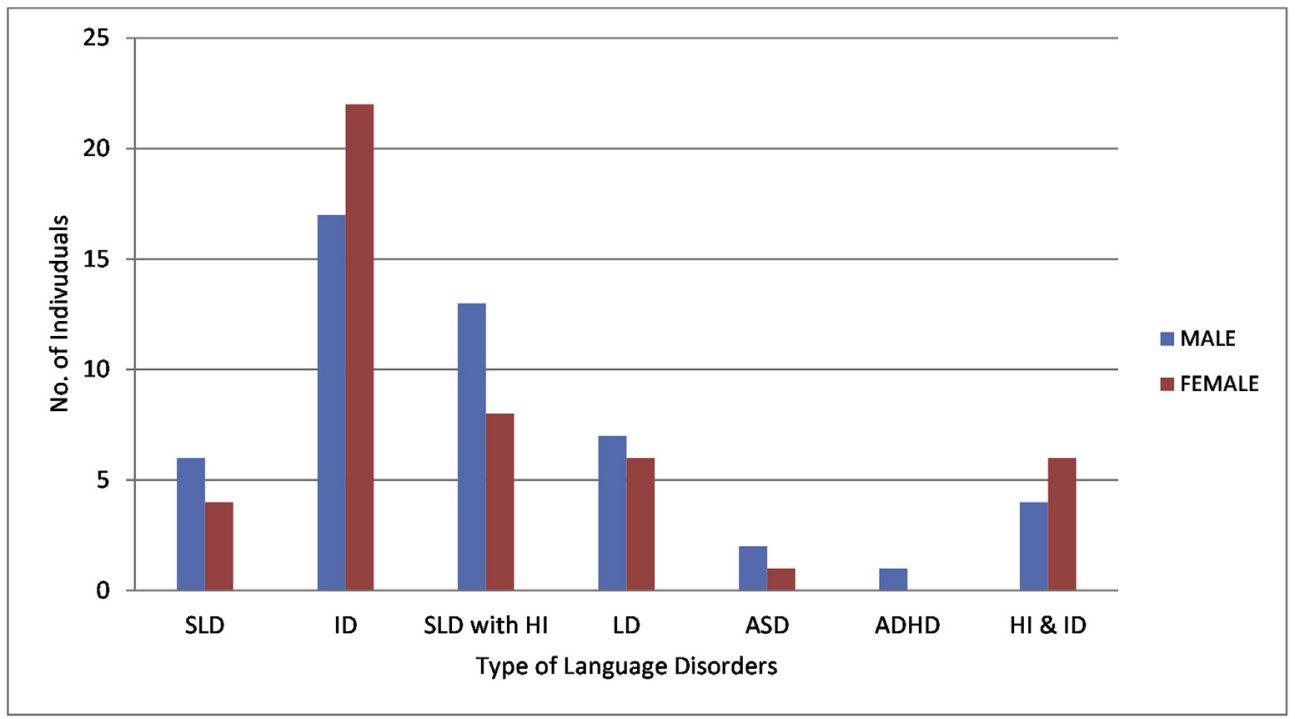

Fig. 2. Gender distribution of language disorders evaluated in North and Middle Andaman \& Nicobar Islands

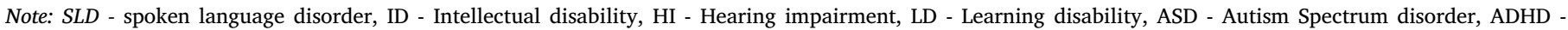
Attention deficit hyperactivity disorder.

revealed that more men were affected than women. This is in par with findings from various other studies. ${ }^{18,21,22}$ One contributing factor could be noisy work environments that are primarily male dominant. Hence, a higher incidence of hearing loss in males could be attributed to noise exposure during this phase. Literature also reports higher incidence rates in males when compared to females even in participants with no noise exposure, ${ }^{21}$ hence resonating with the present study. Hence, the combination of two factors: aging and prolonged noise exposure may add up to present more deleterious effect as seen by the male geriatric population. ${ }^{23}$

\subsection{Speech and language problems}

An age-wise comparison revealed a higher prevalence of speech and language disorders in the pediatric population than the adult population. A gender wise comparison revealed a higher prevalence rate in males than females. An overall higher rate in the occurrence of language (55.5\%) when compared to speech (45.5\%) disorders were observed.

Considering language disorders, a higher rate of prevalence of Intellectual disability (52\%) was observed followed by academic difficulties (17.3\%), and hence by pure spoken language disorders (13.3\%). The restricted number of rehabilitative services available in these islands offers a reduced scope for prevention at the primary (awareness activities), secondary (identification), and tertiary (rehabilitative services) levels. The poor availability of adequate rehabilitative services could be an attributing factor for this prevalence high rate. Poor availabilities of special educators/special school for these children could be another contributing factor.

Considering speech services, a higher prevalence rate of voice disorders $(58.33 \%)$ was observed, followed by that of fluency disorders (16.7\%). Poor awareness regarding vocal hygiene and voice use, 


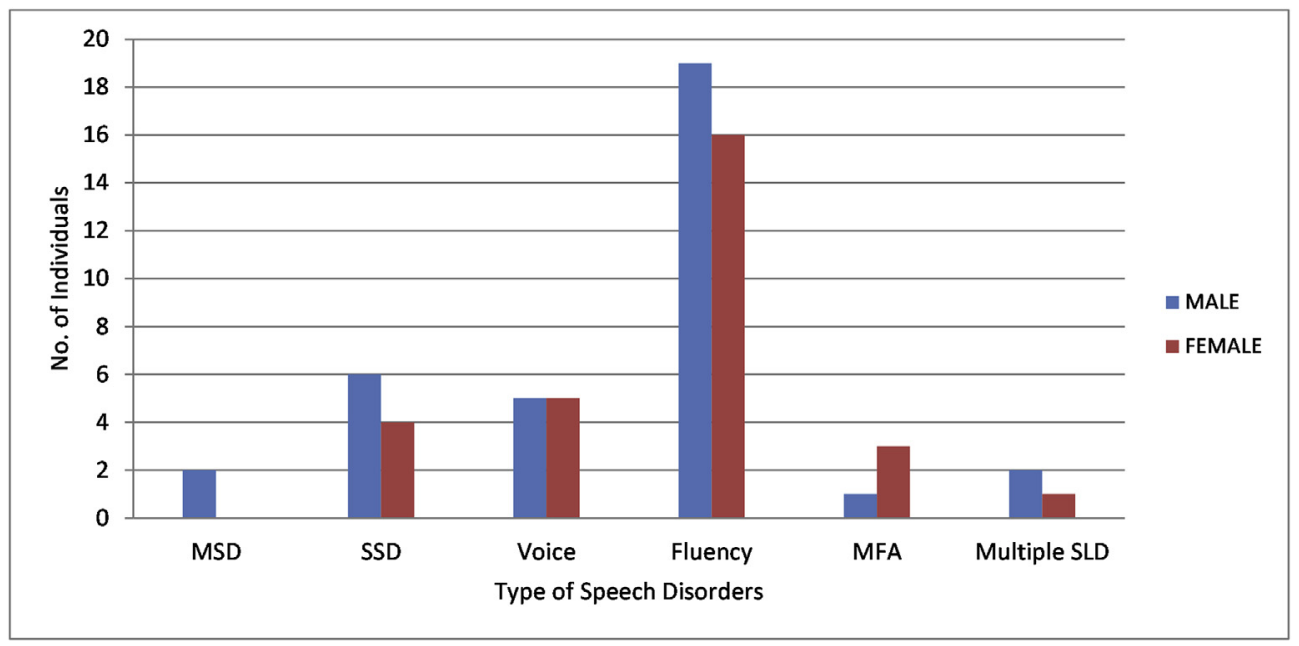

Fig. 3. Gender distribution of speech disorders evaluated in North and Middle Andaman \& Nicobar Islands.

Note: MSD - Motor Speech Disorder; SSD - Speech Sound Disorder; MFA - Maxillofacial Anomalies; Multiple SLD - Multiple speech and language disorder.

coupled with reduced availability of voice therapists and ENT specialists could be a factor contributing to the higher prevalence of voice disorders. Studies have reported that the effort put forth for language dominance may result in errors in a fluent speech that may further manifest as fluency disorders. ${ }^{24}$ The six languages spoken by the population of the Andaman and Nicobar Islands, as reported by the Census of India $2011,{ }^{4}$ could hence act as a contributing factor for the higher prevalence rates of fluency disorders.

The present study revealed a gradual decrease in the prevalence of speech and language disorder with an increase in age as reflected by the results of various other studies in the literature. ${ }^{5,10,11}$ Some studies have also reported that, as age increases, young children tend to outgrow their communication difficulties and improve their speech and language skills. ${ }^{25}$

\section{Summary and conclusions}

The present study was conducted to determine the prevalence of communication disorders in North and Middle Andaman, of the Andaman and Nicobar Islands. The study was carried out in two phases. Phase one included a door to door survey across areas around three major towns of the Andaman Islands. Phase two involved a two-day camp providing diagnostic and rehabilitative services to individuals with communication disorders. The estimated prevalence of communication disorder in the towns of North and Middle Andaman was found to be $3.38 \%$. This percentage of communication disorders was found to be similar to the prevalence data obtained from the Lakshadweep Islands and some rural parts of the Indian mainland. The increased prevalence rate of communication disorders stresses the need for better awareness among the population and increase the availability of rehabilitative services by implementing primary, secondary, and tertiary prevention for persons with communication disorders.

\section{Declaration of competing interest}

Authors have no conflict of interest.

\section{Acknowledgments}

The authors acknowledge the Director of All India Institute of Speech and Hearing, Dr. M Pushpavathi, for permission to conduct this camp and providing adequate support through approvals, grants, and inspiration.

The authors express gratitude to the staffs of Samagra Shiksha
Abhiyan (SMSA), Andaman and Nicobar Islands and the NSS office, the University of Mysore for providing the necessary amenities and other facilities required to conduct this camp.

The authors also extend their warm gratitude to all the 96 NSS volunteers, a batch of 2018-19, from All India Institute of Speech and Hearing for participating in the data collection and compilation procedures.

\section{Appendix A. Supplementary data}

Supplementary data to this article can be found online at https:// doi.org/10.1016/j.cegh.2019.11.006.

\section{References}

1. [Internet]. Asha.org Definitions of Communication Disorders and Variations. 2019; 2019. [cited 11 May 2019]. Available from https://www.asha.org/policy/RP199300208/.

2. Organization WH. World Report on Disability 2011. 2011; 2011.

3. Organization WH. State of Hearing and Ear Care in the South East Asia Region. WHO Regional Office for South East Asia. WHO-SEARO. SEA/Deaf/92009.

4. Census2011.co.in. Literacy Rate of India-population Census. 2011; 2011 Accessed 05.05.19 http://www.census2011.co.in/literacy.php.

5. Konadath S, Prabhu P, Kasturi VJ, et al. Prevalence of communication disorders in Port Blair-Andaman and Nicobar Islands. Clinical Epidemiology and Global Health. 2019 Aug 3 (in press).

6. Sinha SK, Shivaswamy J, Barman A, Seth D, Seshadri D, Savithri S. Prevalence of communication disorders in a rural population at taluq level of Gujarat, India. Clin Epidemiol Glob Health. 2017;5:73-78.

7. Mishra A, Verma V, Shukla GK, Mishra SC, Dwivedi R. Prevalence of hearing impairment in the district of Lucknow, India. Indian J Public Health. 2011:55:132.

8. Das S, Biswas A, Roy T, et al. A random sample survey for prevalence of major neurological disorders in Kolkata. Indian J Med Res. 2006;124:163.

9. Ganesh K, Das A, Shashi J. Epidemiology of disability in a rural community of Karnataka. Indian J Public Health. 2008;52:125-129.

10. Bhagya B, Ramakrishna A. Prevalence of mental retardation among children in Mangalore. Nitte Univ J Health Sci. 2013;3:63.

11. Konadath S, Suma C, Jayaram G, Sandeep M, Mahima G, Shreyank P. Prevalence of communication disorders in a rural population of India. J Hear Sci. 2013;3:41-49.

12. Konadath S, Chatni S, Lakshmi M, Saini JK. Prevalence of communication disorders in a group of islands in India. Clin Epidemiol Glob Health. 2017;5:79-86.

13. Paniagua FA. Culture-bound Syndromes, Cultural Variations, and Psychopathology. Handbook of Multicultural Mental Health. Elsevier; 2000:139-169.

14. Ziglio E, Currie C, Rasmussen V. The WHO cross-national study of health behavior in school-aged children from 35 countries: findings from 2001-2002. J Sch Health. 2004; 74:204-206

15. Campbell TF, Dollaghan CA, Rockette HE, et al. Risk factors for speech delay of unknown origin in 3-year-old children. Child Dev. 2003;74:346-357.

16. Anitha T, Yathiraj A. Modified High Risk Registers (HRR) for Professional and Nonprofessional Formulation and its Efficacy. 2001; 2001 Independent Project submitted to Univ. of Mysore, as a part fulfillment of M. Sc.(Sp. \& Hg.).

17. Clark JG. Uses and abuses of hearing loss classification. Asha. 1981;23:493-500.

18. Cruickshanks KJ, Wiley TL, Tweed TS, et al. Prevalence of hearing loss in older adults 
in Beaver Dam, Wisconsin: the epidemiology of hearing loss study. Am J Epidemiol. 1998;148:879-886.

19. Park YH, Shin S-H, Byun SW, Kim JY. Age-and gender-related mean hearing threshold in a highly-screened population: the Korean National Health and Nutrition Examination Survey 2010-2012. PLoS One. 2016;11:e0150783.

20. Huang Q, Tang J. Age-related hearing loss or presbycusis. Eur Arch Oto-RhinoLaryngol. 2010;267:1179-1191.

21. Pearson JD, Morrell CH, Gordon-Salant S, et al. Gender differences in a longitudinal study of age-associated hearing loss. J Acoust Soc Am. 1995;97:1196-1205.

22. Helzner E, Cauley J, Pratt S, Wisniewski S, Zmuda J, Talbott E. Race and sex differences in age-related hearing loss: the health, ageing and body composition study. Noise Health. 2006;8.

23. Kujawa SG, Liberman MC. Acceleration of age-related hearing loss by early noise exposure: evidence of a misspent youth. J Neurosci. 2006;26:2115-2123.

24. Lim VP, Lincoln M, Chan YH, Onslow M. Stuttering in English-Mandarin bilingual speakers: the influence of language dominance on stuttering severity. J Speech Lang Hear Res. 2008.

25. Owens R, Metz D, Farinella K. Introduction to Communication Disorders. UK: Pearson Education; 2015 